\title{
COMMENT
}

VACCINES LesSons from the long war to eradicate polio $\mathbf{p . 4 6}$
RENEWABLE ENERGY Lithium

feeds the chase for a

superbattery $\mathbf{p . 4 4 8}$
PSYCHOLOGY How jokes reveal the workings of the mind $\mathbf{p . 4 5 0}$

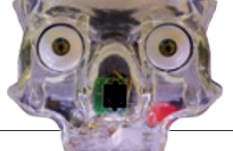

ART EXHIBIT Visions of the future for the human body $\mathbf{p . 4 5 1}$

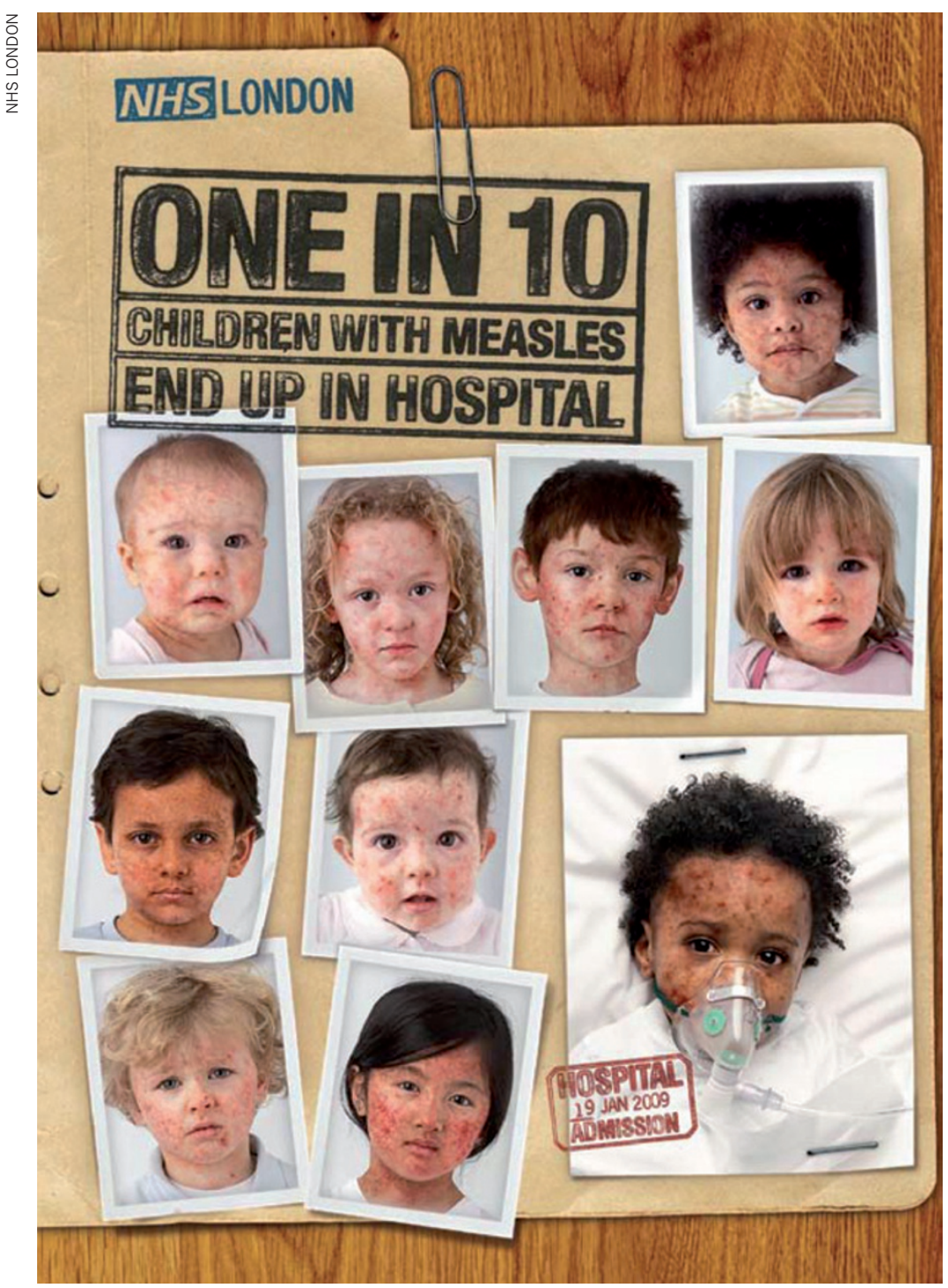

Are campaigns like this the best way to reach doubting parents?

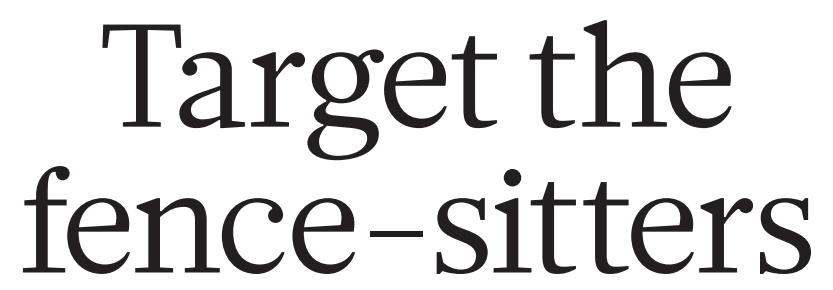

Past waves of vaccine rejection in industrialized nations have a lot to teach us about preventing future ones, argues Julie Leask.
Tmmunizing a child requires a leap of faith by any parent or carer. Picture Emily, a new mother, whose healthy eight-week-old baby is scheduled to receive vaccines against up to eight diseases that Emily has never seen. Emily feels wary of expert knowledge. She is concerned that the vaccines could weaken her baby's immune system and is anxious about the technologies of modern life. Prosaically, she feels daunted by the trip to a clinic full of sick people where there might not be anywhere to change or feed her baby comfortably.

Emily seeks information online. Three of the first ten search results link vaccines to problems such as allergies, autism, diabetes and cancer. One might expect Emily and many other new parents in industrialized countries to be rejecting immunization.

Surprisingly, levels of support for childhood vaccinations are generally high and stable. In countries that are members of the Organisation for Economic Co-operation and Development, 95\% of children, on average, received all three primary doses of diphtheria-tetanus-pertussis (DTP) vaccine in 2009. The United Kingdom's measlesmumps-rubella (MMR) immunization rates have clawed back to $89 \%$ from a 2004 low of $80 \%$ that was caused by the now debunked claims of a link to autism ${ }^{1}$ (see 'The cost of a scare'). Coverage for other vaccines was unaffected. The United States has recorded 95\% DTP immunization rates for toddlers and rates of children receiving no vaccines remain stable at four to six per thousand ${ }^{2}$. Australia's immunization rates have increased steadily over the past decade to $92.5 \%$ of two-yearolds fully vaccinated in $2008^{3}$. Five out of the six World Health Organization regions achieved a $90 \%$ reduction in measles deaths between 2000 and 2010. Finland, Cuba, England and Wales, Brazil, Mexico, the United States, Canada, South Korea and Australia are at, or near, measles elimination.

\section{CLIMATE OF DISTRUST}

But dig a little deeper and there are grounds for concern. From 2008 to 2009, the United States recorded a $3 \%$ decline in MMR

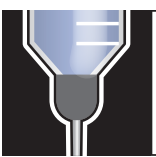

VACCINES

New promise, old doubts nature.com/vaccines 
immunization rates to $90.6 \%{ }^{4}$. In the United States, Britain and Australia, up to one-third of parents report concerns about the number of vaccines that babies are now receiving and are more distrustful of newer vaccines, a phenomenon that may increase as more are introduced. A survey in 200809 found that up to about one-fifth of parents from five European countries reported doubts about having their child vaccinated ${ }^{5}$.

Communities of parents - particularly those who espouse the alternative lifestyles, anthroposophical or religious beliefs that oppose vaccination - continue to contribute to outbreaks of diseases such as pertussis, measles and Haemophilus influenzae type b (Hib).

But the greatest causes for concern are unfounded scares around particular vaccines - leading to anything from small downturns in immunization rates to the cessation of entire programmes. Japan had one such scare in the 1970s, when the deaths of two children within 24 hours of receiving the DTP vaccine led to the suspension of that programme and then its resumption two months later with a primary dose beginning at two years of age rather than at three months. A pertussis epidemic followed in 1979 with more than 13,000 cases leading to 41 deaths $^{6}$. Britain's recent MMR experience pales in comparison with its own DTP scare of the late 1970s when the vaccine was linked to encephalopathy. Immunization rates fell from $80 \%$ to $30 \%$; there followed
70 deaths among more than 300,000 cases of pertussis ${ }^{7}$.

As a social scientist specializing in immunization take-up, it is clear to me that we can and must work harder to head off such scares by better engaging fence-sitting parents and wavering health professionals. Just as vaccine programmes must be informed by sound research, so too must communication strategies.

\section{SCARE STORIES}

What makes a vaccine scare take hold? It is a complex interplay of factors embedded in a country's historical, social and political context.

Sporadic media reports do not immediately affect vaccine uptake. The media tends to sideline groups that criticize vaccines until a prominent figure champions a theory against a backdrop of mistrust in government. The MMR-autism and DTPencephalopathy links were advanced by doctors committed to their hypotheses; both were charismatic individuals from respected institutions laying their theories Galileo-like at the door of the scientific church.

The British doctor Andrew Wakefield, who linked the MMR vaccine with autism, juxtaposed stereotypes of hard-pressed parents and kindly clinicians against those of unyielding health authorities. His views fed a hunger for autism's cause. A similar hunger drove the now equally discredited attempt to link the DTP vaccine with sudden

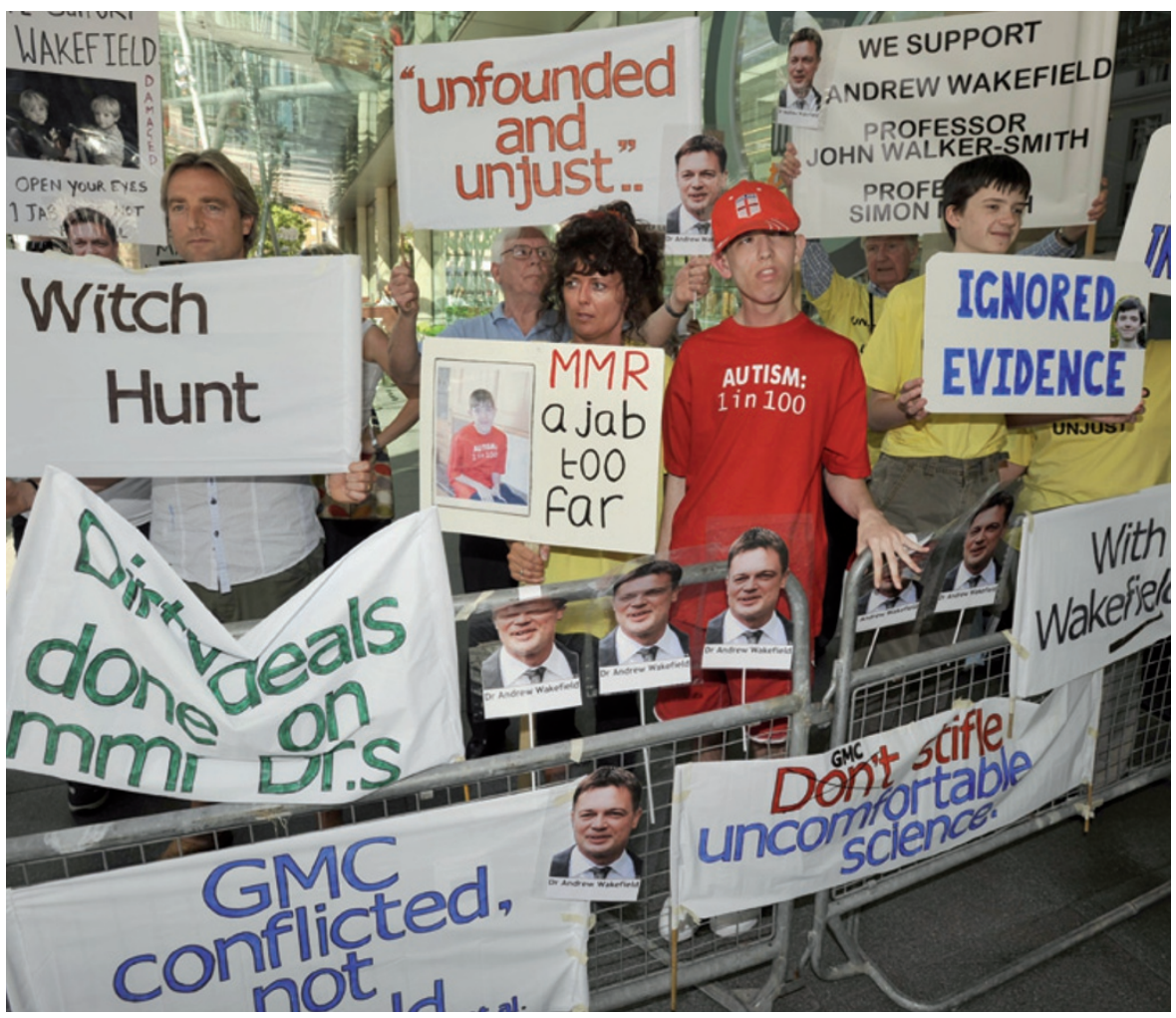

UK doctor Andrew Wakefield retained support when he was struck off the medical register in May 2010.

infant death syndrome (SIDS), which lost its currency by the late 1990s with better understanding of the precursors of SIDS.

Such figures can give a scare enough traction or politicization to become mainstream. At this point, media editors often marginalize medical reporters who are knowledgeable enough to discern quality of evidence in favour of general newshounds. Reports may then begin to give weight or 'false equivalence' to theories with scant scientific support.

Health professionals are key in tipping a scare towards widespread vaccine rejection. They too are affected by persistent public messages. In 1976, at the height of Britain's DTP scare, up to one-third of general practitioners (GPs) were advising against pertussis immunization ${ }^{8}$. In 1998, just four months after the publication that triggered the MMR scare, $13 \%$ of GPs and $27 \%$ of practice nurses in north Wales thought it very likely or possible that the vaccine was associated with autism ${ }^{9}$. Committed, confident and knowledgeable health professionals are the cornerstone of successful immunization programmes. Parents repeatedly rate them as their most trusted source of advice. So if doctors and nurses lose confidence, it can have a profound effect.

Many commentators assume that a failure to vaccinate is caused by parents poor understanding of immunization. Under this logic, parents who are given scientific facts will abandon their erroneous beliefs and proceed to vaccinate. However, the work of Nobel laureate Daniel Kahneman and Amos Tversky and others on heuristics and biases demolished these assumptions. Decisions about whether to immunize are not usually made rationally nor at one moment in time. And knowledge rarely predicts vaccine uptake - indeed, refusers are more likely to have university education than those who accept vaccination. Hence scientific arguments alone will not sway them, and may even increase their resolve to not immunize.

\section{THREE STEPS}

There are three ways in which governments can maintain or retain high uptake of safe, effective childhood vaccines. First, they must minimize the structural barriers. For every concerned parent or carer like Emily, there is another who finds it difficult to get her child immunized on time because of practical barriers such as a lack of transport, money or help to mind other children.

Countries with high child-immunization rates have well-oiled systems: free and accessible vaccines, national record keeping and reminders. Financial incentives for parents and providers and sanctions such as exclusion of unvaccinated children from childcare during outbreaks or compulsory 


\section{THE COST OF A SCARE}

In the wake of the now-debunked claims in 1998 of a link between the measles, mumps and rubella vaccine and autism, vaccination dropped and measles cases rose in England and Wales.

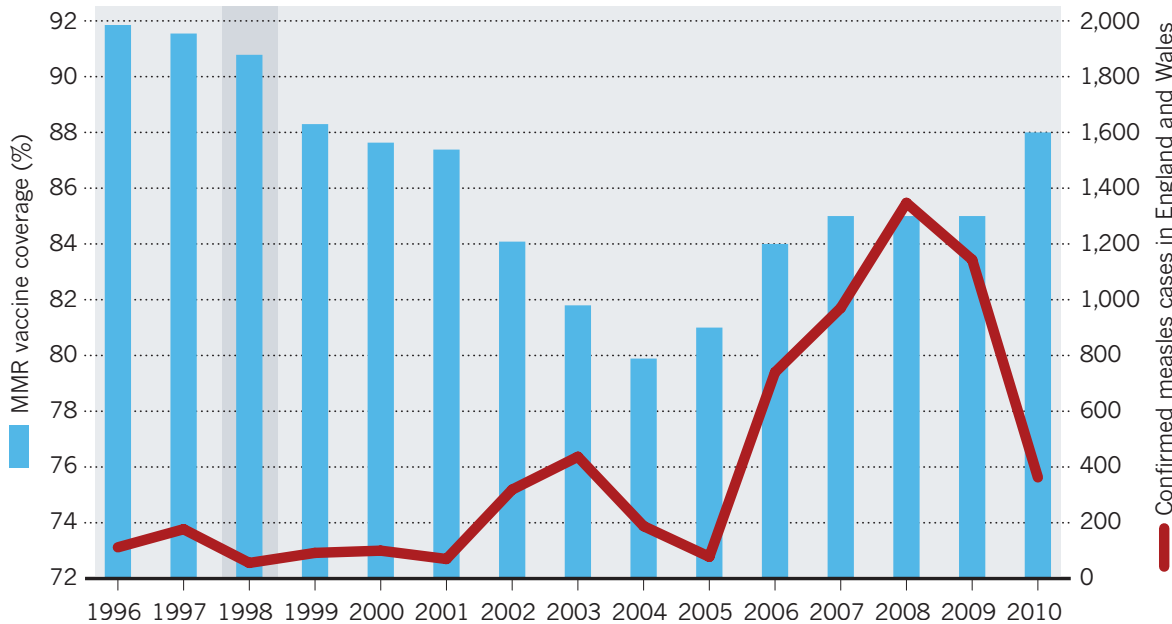

immunization also have an effect. But no intervention works in isolation and programmes must be comprehensive to succeed.

Second, communication strategies need to be tailored to groups for whom real gains can be made. Between $3 \%$ and $7 \%$ of all children are under-vaccinated because their parents refuse some or all vaccines; these parents tend to have intractable views. Hesitant parents such as Emily are a larger and more attentive group who usually vaccinate but might delay or decline a stigmatized vaccine.

Communication with this group should be the priority and needs to be informed by better evidence. Governments and health organizations must move beyond deficit models of communication that assume the public to be passively awaiting their information fill. Rather, they must recognize that people interact with information according to their experiences and social settings ${ }^{10}$.

Tools can include: motivational interviewing - where health professionals guide hesitant parents to engage with the issue and elicit motivation for change while respecting their autonomy; decision aids (such as that of Australia's National Centre for Immunisation Research and Surveillance; go.nature.com/hp6156) that help parents to consider the pros and cons of their options; peer-led and expertresourced parent discussion groups; and social-media strategies that address rumours and promote vaccination.

Third, health professionals must be kept on board. This involves initiatives to sustain their confidence in safe vaccines and raise their competence to address parental concerns. More time should be spent on immunization in medical and nursing curricula; continuing education should be provided; and timely updates issued when

scares arise. More pragmatically, systems should be put in place to prompt doctors or nurses when a vaccine is due or overdue, to evaluate their performance as vaccination providers, and to enable suitably qualified health professionals to give a vaccine without a doctor's involvement each time.

Better government engagement of health professionals and the public will also enhance systems for reporting and acting
"An

atmosphere

that censors

any public

concerns can

unwittingly

alienate

hesitant

parents." following immunization. An atmosphere that censors any public concerns can unwittingly hinder efforts to hear and respond to real problems and can alienate hesitant parents, the most important audience to keep on side.

In sum, anti-vaccine sentiment is inevitable, so the professionals involved should be prepared. It is too late once a scare arrives. Countries need to monitor and engage with their public and professionals and develop communication plans pro-actively. In that communication they also need to assure the public that a truly robust programme of proactive research continues to explore the safety of existing and emerging vaccines. The United States has led the way, for example, in holding workshops with the public that informed the government's vaccine safety research agenda.

\section{THE FUTURE}

Many questions remain about the precursors to large declines in vaccine acceptance. The UK and US governments have ongoing surveys to measure attitudinal trends. Other governments should commit to similar evaluations both of coverage and of public attitudes, and surveys should be harmonized for comparison across countries and over time ${ }^{5}$. Furthermore, researchers should ground their studies in theories of health behaviour and use validated measures. Such measurement needs to be complemented by qualitative enquiry, asking the 'why' and 'how' questions. For example, interviews with new parents could explore how they negotiate anti-vaccination information from their social-media networks.

The MOTIV (Motors of Trust in Vaccination) Think Tank initiated by Sanofi Pasteur and the London School of Hygiene and Tropical Medicine was established in December last year to better understand the diverse factors that drive immunization rates. This multidisciplinary group has proposed a research agenda centred on three broad areas: decision-making, social norms and communication. Questions include: what cognitive processes underpin vaccine decision-making and what are their relative weights in different contexts? How do social networks shape disease and vaccine perceptions? How does public engagement influence levels of trust in vaccines and vaccination-promoting groups or organizations? The group is launching an international Centre for Decision-Making on Immunisation to take forward multidisciplinary research to address these questions.

The safest and most effective vaccines are of little use if too few people take them. Public support for immunization remains high in most industrialized countries, but vaccine scares will continue. Our strategies must be tailored to our times - they must be consultative and grounded in sociology, psychology and communication science.

Julie Leask is at the National Centre for Immunisation Research and Surveillance, Discipline of Paediatrics and Child Health, School of Public Health, University of Sydney, New South Wales 2006, Australia. e-mail:JulieL3@chw.edu.au

1. Quarterly Vaccination Coverage Statistics for Children Aged up to Five Years in the UK (COVER programme): July to September 2010 in Health Protection Report 4(38) (Health Protection Agency, 2010).

2. Centers for Disease Control and Prevention. Morb. Mortal. Wkly Rep. 59, 1171-1177 (2010).

3. Hull, B. P., Mahajan, D., Dey, A., Menzies, R. I. \& McIntyre, P. B. Commun. Dis. Intell. 34, 241-258 (2010).

4. National Committee for Quality Assurance. The State of Health Care Quality (NCQA, 2010).

5. Stefanoff, P. et al. Vaccine $\mathbf{2 8 , 5 7 3 1 - 5 7 3 7}$ (2010).

6. Gangarosa, E. J. et al. Lancet 351, 356-361 (1998).

7. Nicoll, A., Elliman, D. \& Ross, E. Br. Med. J. 316, 715-716 (1998)

8. Swansea Research Unit of the Royal College of General Practitioners. Br. Med. J. 282, 23-26 (1981).

9. Petrovic, M., Roberts, R. \& Ramsay, M. S. Br. Med. J. 322, 82-85 (2001).

10. Leach, M. \& Fairhead, J. Vaccine Anxieties: Global Science, Child Health and Society (Earthscan, 2007). 